\title{
Relationship of Achievement Goal Profiles With English Listening Comprehension and Metacognition in China
}

\author{
Kelly M. Parker \\ Beijing Normal University - Hong Kong Baptist University United International College, Zhuhai, China
}

\begin{abstract}
This study explores the relationships between mixed achievement goals and metacognition in Chinese English major students' in-class listening comprehension and strategy selection, continuing threads of traditional research into the receptive language modalities of reading and listening. Stereotypes of foreign English teachers are also examined for their positive and negative effects on student affect, cognition, and metacognition. Choosing an appropriate achievement goal construct from several paradigms, the researcher chooses a mastery and performance dichotomy, with strong and weak tendencies, to create four achievement goal profiles within a group of 84 sophomore English majors in Mainland China. Methodology is hybrid, with quantitative classroom research data and qualitative teacher reflections. The main findings are that subjects with strong mastery achievement goals measure high on listening comprehension tests and demonstrate heightened competence with top-down listening comprehension strategies. Other findings confirm prior suggestions that students with heightened comprehension may not always use, or be cognizant of, bottom-up learning strategies. Suggestions for foreign and local researchers include the development of socioculturally specific, yet parsimonious, achievement goal constructs for Chinese postsecondary students of English, so that curriculum developers and teachers can simultaneously teach a language of metacognition to all students, while enhancing their listening comprehension.
\end{abstract}

Keywords: listening comprehension, achievement goal profile, metacognition, learning strategies, Chinese students

\section{Introduction}

A recent study by He (2008) suggests that Chinese English as a foreign language (EFL) reading students who are attracted to strong mastery eagerly practice self-regulated learning strategies, while extrinsically motivated students, obsessed with exam performance, are reticent to change their old strategies. Both reading and listening comprehension are receptive language skills, making reading comprehension research of great value in understanding listening comprehension, but listening "involves serious time constraints on processing" (Arnold, 2000 , p. 779) that readers do not encounter. This study attempts to expand the corpus of listening comprehension knowledge, using some insight from reading comprehension research, by focusing on achievement goals and strategy use in the Chinese postsecondary EFL context.

Kelly M. Parker, lecturer at Beijing Normal University - Hong Kong Baptist University United International College, M.A. in Teaching English as a Second Language, University of Nevada at Reno, Graduate Certificate in Postsecondary Reading and Learning, California State University at Fullerton. 
The primary objective of this study was to find out if achievement goal constructs are reliable predictors of listening proficiency, or of student preferences for bottom-up or top-down processing during classroom listening laboratory activities. Based upon research in reading comprehension (He, 2008) and listening comprehension (Shang, 2008) with Chinese students, and the researcher's initial observations as a teacher in China during 2009, it was hypothesized that students with strong mastery achievement goals will prefer using top-down strategies, while those with weak achievement goals, mastery or performance, will be ambivalent about strategy use. It was also predicted that students with a combination of both mastery and performance achievement preferences will trend toward higher scores on proficiency tests. To test these hypotheses, a repertoire of listening strategies, half bottom-up and half top-down, were modeled for 84 students throughout the first semester of their sophomore year at Sha'anxi University of Science and Technology. These students were given opportunities to practice this strategy repertoire every week, and assessed four times throughout their semester-twice in the use of bottom-up listening strategies and twice in the use of top-down listening strategies.

A secondary objective of this study was to observe the effects of heightened metacognition on strategy selection and listening proficiency. The rationale for this was that learning a strategy repertoire would entail development of student metacognition. Though it might be difficult for second language learners to articulate metacognition, it was hypothesized that strongly motivated students would sense when to use or not use listening comprehension strategies to repair cognition. Assuming that metacognition would be very difficult to measure, as the literature suggested that comprehension monitoring is mostly done automatically (Casanave, 1988, p. 289), the research design plan was simply to observe and reflect upon ways Chinese EFL students could be taught to communicate about their cognitive development.

English teachers in Chinese universities come from both inside and outside China. These two teacher pools ostensibly weigh the purposes of instruction differently, placing differing values on meaning, content, and language learning (Casanave, 1988, p. 286).

Foreign teachers from Inner Circle English-speaking regions (Kachru, 1985, 1997), such as the United Kingdom, North America, Australia, and New Zealand, primarily tasked with teaching in oral English, often bring anxiety to the classroom. Despite a typical excitement for communicative language teaching, teachers who:

Have never taught within the context of an Eastern culture may have difficulty in dealing with the apparent lack of response in a classroom, and may interpret as dullness or lack of cooperation what is in fact a reticence based on a cultural form of respect. (Boyle, 2000, p. 148)

This difficulty may stem from an unawareness of the risk-taking and self-exposure that students must experience in classes emphasizing communicative skills practice (Arnold, 2000).

Personal preferences, attitudes and traits are emphasized in the West (Kitayama, Duffy, \& Uchida, 2007; Kitayama, Park, Sevincer, Karasawa, \& Uskul, 2009; Markus \& Kitayama, 1991). Motivation, to an independent-minded Westerner, is toward "those actions that allow expression of one's important self-defining, inner attributes" (Markus \& Kitayama, 1991, p. 230). For a more interdependent Chinese person, however, motivation is more likely toward "actions that enhance or foster one's relatedness or connection to others" (Markus \& Kitayama, 1991, p. 231) or "to maintain social approval" (Kitayama et al., 2009, p. 240). This mismatch, between foreign English teachers' notions of self-preference motivation and Chinese students' notions 
of social-acceptance motivation, affects the types of communication activities possible in English as a Foreign Language (EFL) classrooms, because "a consideration of the social context and the reactions of others may also shape some basic, nonsocial cognitive activities, such as categorizing and counterfactual thinking" (Markus \& Kitayama, 1991, p. 231). For example, Chinese students may associate people and objects more closely than in Western teachers' schemata, making it a challenge to give instructions. They may also hesitate to disagree with texts, making it difficult to elicit critical thinking responses in English classes, or refuse to be forthright about their cognitive difficulties, making it difficult to accurately measure motivation and strategy use.

Some promotion of motivation is evident in typical English listening textbooks used in China, indicating potential interest in student motivation research amongst the community of practice. Minimal attention is paid to motivation, however. For example, one textbook used at Sha'anxi University of Science and Technology mentions motivation only under one heading called Listening Strategy, with a suggestion that "Students should be fully motivated while they are listening, not just guessing and ticking the right answer" (Shi, 2006, p. 2). Since a performance-driven student's perspective is likely to be focused on the latter, ticking the right answer, this suggestion is somewhat useless. Without a theoretical framework for motivation, the foreign English teacher has no recourse but to transmit a Western notion of motivation to students.

Cognitive and associative differences between cultures were carefully considered in choosing the appropriate achievement goal construct for this study. A simple split of mastery and performance (Pintrich, 2000, 2003) was initially appealing, as it informed a then recent study of English reading comprehension with Chinese EFL students (He, 2008). Splitting the performance achievement goal into performance-approach and performance-avoidance profiles (Elliot, 1999) was considered, as this researcher had observed many Chinese students who had seemed to fit those descriptors. Splitting the mastery goal into mastery-approach and mastery-avoidance profiles (Elliot \& McGregor, 2001) was also considered, as this researcher had also observed a minority of students who had seemed to fit these profiles.

Though ostensibly scientific, most of these achievement goal constructs threatened to distance this study from its more simplistic goal of finding causal links from mixed achievement goals, to either listening proficiency or listening strategy selection. Considering the wisdom of Pastor, Barron, Miller, and Davis (2007), that,

When a researcher uses more complex models of goal orientation along with a multiple goal perspective, another level of complexity is added to the already difficult tasks of: (1) describing the typical goal orientation profiles of students in a sample and (2) analyzing the relationships of goal orientation with other variables. (p. 9)

a parsimonious decision was made to adhere to Pintrich's mastery-performance dichotomy $(2000,2003)$.

The theoretical implications of this study are that it confirms observations made by others, that high-mastery achievement goal profiles predict higher proficiency in the use of top-down strategies in comprehension (He, 2008; Shang, 2008), and that multiple goals of mastery and performance drive higher performance in proficiency tests (He, 2008).

The practical implications of this study are that multiple achievement goals might have a positive influence on listening comprehension, by influencing strategy selection and use. Metacognition enables students to select appropriate strategies depending on their preferences and listening purposes. If students are made even more 
aware of the role of mastery in their test performance, they may become more engaged in practicing English listening outside of the classroom, so that they can perform well in typical classroom listening assessments.

The relationship of mastery and performance achievement goals and metacognition was explored for an entire semester, with the researcher previously biased toward the efficacy of multiple goals in language reception. However, the purpose was not to zealously argue for multiple goals in curriculum or the classroom, but to encourage more precise research of the interplay of achievement goal constructs and metacognition in Chinese postsecondary EFL listening comprehension. With contextual data, Chinese and foreign educators might be better able to work together, enhancing English listening comprehension in Chinese postsecondary EFL classrooms.

\section{Method}

Selected participants were conveniently sampled from 84 English-major students enrolled in three second-year English Listening classes at Sha'anxi University of Science and Technology, Xi'an during the fall 2009 semester. 75 students, or $89 \%$, were females and 9 students, or $11 \%$, were males. Subjects ranged from age 19 to 24. Most of these students were on track to pursue post-graduate studies in English, and become future English teachers in China, pending success in the high stakes Test for English Majors (TEM-4), which is typically given to English majors during the spring semester of the second year at China universities.

As these students were all facing the TEM-4 during the following spring semester, informal assessments of listening proficiency were given at the beginning and end of the prior fall semester, with a mock test of Part III (Listening Comprehension), using text from a typical TEM-4 preparation book to inform mock test creation (Shen, 2003). Each test had 25 questions, with each answer multiplied by four to scale to 100. An average of these two scores was used as an estimate of each student's proficiency level in this study.

For each of the 16 weeks of the fall semester, a new listening comprehension strategy was modeled for the students. They were given opportunities to practice in their listening laboratory classroom, and encouraged to practice their growing strategy repertoire outside of class. This repertoire of 16 listening comprehension strategies was grouped into four categories: (1) note-taking; (2) test-taking; (3) comprehending; and (4) vocabulary-building. These 16 strategies were also divided between eight top-down (TD) and eight bottom-up (BU) listening comprehension strategies, but simply presented to the students as learning strategies, with no explanation of TD or BU classifications.

Students were tested twice on listening tasks involving TD strategies, and twice on listening tasks involving BU strategies, with their scores scaled to 100 and averaged for this study. A final exam of 25 multiple-choice questions measured each student's knowledge of the entire listening comprehension strategy repertoire.

Achievement goal profiles were measured by students' performance on in-class assignments (mastery), final exam (performance), and overall grade (performance and mastery). A median-split method, favored by Pintrich (2000) but criticized by Pastor et al. as "seductively easy" (2007, p. 12), was used to place students into four quadrants. These four quadrants represented the same individual achievement goal categories as in the $\mathrm{He}(2008)$ study: (1) strong-mastery, strong-performance (SMSP); (2) strong-mastery, weak-performance (SMWP); (3) weak-mastery, strong-performance (WMSP); and (4) weak-mastery, weak-performance (WMWP). 
Altogether there were seven quantitative assessments: two on BU strategy competence, two on TD strategy competence, two on listening proficiency, and one on strategy repertoire knowledge. The BU strategies were (1) a word recognition stratagem for rapid decoding and meaning construction while listening and (2) a word sorting and noticing stratagem for rapid meaning construction while listening and context exploration after listening. The TD strategies were (1) drawing pictures during a story recording and (2) predicting gap content in a story. Assessments of BU and TD strategy competence were compared to the four achievement goal profiles, to see if any relevant patterns were apparent.

Qualitative data was informally collected, consisting of teacher reflections of student behavior and classroom discussions. Two formal means of data collection, reflection journals and strategic reasoning responses, were carefully considered, but deferred until a future study. Reflection journals require the vocabulary of metacognition, which was slowly developed over the semester. To elicit journals from EFL learners still struggling with word recognition and meaning skills risked very general comments likely to be of no use for research. Ericsson and Simon (1980) claim that "inconsistent reports can be produced as a result of probes that are too general to elicit the information actually sought, and as a result of subjects' use of inferential processes to fill out and generalize incomplete memories" (p. 247).

Strategic reasoning, which has been effective in teaching reading because it heightens awareness of how processes are done, would also have been difficult in just one semester because "learning to teach and assess strategic reasoning is a trial-and-error process requiring much reflection on the part of the teacher" (Herrmann, 1992, p. 433).

There were other means available for collecting qualitative data, such as questionnaire surveys, but the reliability of these was questionable given the new nature of the teacher-researcher and students' relationship. Students, of any culture, are prone to performance anxiety with "activities that require self-investment in front of others when a non-threatening atmosphere has not been established" (Arnold, 2000, p. 778). Since a trust relationship would take time to develop, qualitative written data-collection methods were deferred until future studies.

\section{Results}

WMWP students represented the mode of 34 students, followed by SMWP at 23 students and SMSP at 19 students. Least represented were WMSP students, of which there were only 8 out of 84 total students.

Using the average simulated TEM-4 scores as an indicator, students with SMSP and SMWP profiles scored high in listening proficiency, at $85 \%$ and $83 \%$ respectively. WMSP students scored at $74 \%$ and WMWP students scored $58 \%$.

SMSP and SMWP students all tended to do better in TD processing strategies, while the WMWP group did better in BU processing strategies. The breakdown for WMWP (34 students) was 58.8\% BU, 35.3\% TD, and $5.9 \%$ split evenly in their strategy competencies. The breakdown for SMWP (23 students) was $13.0 \%$ BU, $74.0 \%$ $\mathrm{TD}$, and $13.0 \%$ split evenly. The breakdown for SMSP (19 students) was 10.5\% BU, 84.2\% TD, and 5.3\% split evenly. The breakdown for WMSP ( 8 students) was $50.0 \% \mathrm{BU}, 50.0 \% \mathrm{TD}$, and $0.0 \%$ split evenly in their strategy competencies. 


\section{Discussion}

Strong mastery is a common factor in the high proficiency group. This correlates with He's findings (2008). However, proficiency was measured using simulated TEM-4 tests, which may have heightened worry about cognitive performance and negative emotions in some students (Arnold, 2000, p. 779).

Weak mastery is a common factor in the low proficiency group. The average $58 \%$ scores of the WMWP group may suggest that test anxiety is more likely to negatively affect WM or WP profiles. The WMSP group, at $74 \%$, suggests that WM achievement goal profiles may indicate a tendency toward test anxiety unnoticed with the WP students.

The WMWP group does measure a majority percentage of 58.8\% competence for BU strategies, versus $35.3 \%$ for competence in TD strategies, suggesting these students may get flustered with decoding tasks, or may be doing the bare minimum for social acceptance. As Arnold (2000) suggests, "The implication is that if students are worrying about not understanding, they are not giving their full attention to the task at hand" (p. 784). This group's low proficiency score of 58\% may suggest that they were not fully on task. The WMWP group may include those avoiding high performance on tests, perhaps because they do not want to stand out in the group, as well as those students lacking confidence in developing personal mastery of listening comprehension. Future studies that consider the approach and avoidance constructs of performance and mastery may be fruitful in Chinese postsecondary EFL research.

The top scoring profiles, SMSP and SMWP, both have a common factor-high mastery in the achievement goal profile. Both of these profiles strongly tilt toward a preference for top-down strategies. This may be explained by He's finding that the "SMSP goal profile was a stronger predictor of reading achievement than frequency of strategy use" (2008, p. 236) and Casanave's observation 20 years prior that "Good readers, however, do much of their monitoring automatically, without needing to allocate much conscious attention to it, particularly when they are reading for gist or for pleasure" (1988, p. 289). While BU strategies may be more effective for beginners, they may be ignored by advanced listeners who do not really need to be strategic for most listening passages. This could account for the low competence in BU measured by the SMSP and SMWP groups of students, despite their high proficiency in listening comprehension. Since these students did not practice BU strategies very often, they may have simply not developed proficiency with them.

Observation throughout the semester was that less competitive students deliberately tried neither to outshine one another, nor do less than their peers, craftily performing just well enough to slide through tasks. This may not be mastery-avoidance, in the sense that Elliot (1999) or Elliot and McGregor (2001) described, as students did try to reach the minimum bar set by their peers. Perhaps a culturally-specific achievement goal construct, which considers the social context valued by East Asian students described by Markus and Kitayama (1991), would be apropos for defining performance and mastery achievement goals in a Chinese context.

Ideally, a systematic means of collecting qualitative data would have been implemented for any study of achievement goal constructs and motivation. This was not done because the relationship between students and teacher was not fully developed. As more established educators in China use their classrooms and develop trusting relationships with their students, perhaps further action research will emerge, which will include more useful qualitative data, such as reflective journals from students themselves. 
Future research should also consider a variety of listening comprehension assessment instruments. Although using a simulated TEM-4 gave some stability to this classroom research, it may only be useful for measuring performance, not mastery, of listening comprehension. Because of the high stakes of this examination, a simulated TEM-4 might also induce emotional stress on students, which can temporarily skew measurement of normal achievement goal profiles.

The most important future research suggestion might be to develop socioculturally contextualized, yet parsimonious, achievement goal constructs for Chinese tertiary students. Though the method chosen for this study was elegant in its simplicity, it necessitated an arbitrary median split-point for the weak and strong tendencies. This may not be the best approach for further research. In a 2007 analysis of methods for deriving achievement goal constructs, Pastor, Barron, Miller, and Davis heavily criticized the median-split technique:

A problem with median split procedures has to do with the questionable homogeneity of the cases classified in each profile as well as the problematic use of labels such as "low" and "high" to characterize cases falling below and above the median. A solution to the above problem may be to split each goal factor into more than two categories. (p. 13)

An appropriate achievement goal construct for China should at the very least consider the avoidance and approach tendencies in mastery and performance achievement goal profiles (Elliot \& McGregor, 2001; Elliot, 1999), and perhaps even go as far as to redefine the notion of performance and mastery in a Chinese sociocultural context.

There may even be a case for defining situationally dependent goal constructs, as students may have different achievement goal constructs at different times during their academic paths (Barron \& Harackiewicz, 2001; Pintrich, 2000). With the TEM-4 looming every April, for example, second-year Chinese English majors who profile as high-mastery in their fall semesters may switch to a high-performance achievement goal early in the spring, reverting back to high-mastery after their high-stakes test is over.

\section{Conclusion}

In the textbook used by the listening students who were the subject of this research, a disclaimer is made in the introduction:

A fundamental idea underlying this book is that listening is an active process, which employs a variety of active "strategies", such as predicting, matching against our own experience, distinguishing important information from those unimportant, inferring information about the speaker, etc. (Shi, 2006, p. iv)

From this it can be inferred that some curriculum developers are thinking about strategic learning. However, the lack of emphasis on strategy use, within the lessons themselves, is counterproductive. For students to wholeheartedly embrace use of listening strategies, they need encouragement to be strategic and monitor their comprehension. Additionally, students need to become capable of talking about their learning processes. Curricula should include vocabulary terms and a strategy tip for every student lesson, so that students can master discourse about what they know and how they are learning.

With proper training in the language of cognition (metacognition), formal qualitative measures, such as reflective journals or strategic reasoning, are feasible for use with Chinese tertiary students. For English majors in particular, early metacognition will help them become powerful teachers in China's future. Christine Pearson 
Casanave, a longtime advocate of teaching second language students to become more expressive, wrote in 1988 that "to learn to monitor comprehension in the classroom context, less efficient readers and their teachers need to share a language for talking about it" (p. 289). More recently, Casanave has encouraged this free expression up to, and including, post-graduate writing for second language students, suggesting that students may be afraid to write outside of traditional writing conventions (2010, pp. 3-4). As efficient listeners need to share their language of metacognition with teachers, educators need to be cognizant of the restraints students may feel in expressing themselves.

If appropriate achievement goal constructs and surveys can be designed for Chinese EFL students, course instructors can profile their students at intake, as well as key milestones during their post-secondary journey. If enough longitudinal studies are done, curriculum designers can modify activities to correspond to the average student's motivators (and demotivators) throughout each school year. This may help stakeholders decide when to focus on test preparation and when to focus on natural language, for example. If teachers, curriculum designers, and researchers can more precisely understand the achievement goal constructs of Chinese postsecondary EFL students, classroom instruction and curricula can be tailored toward improving both mastery and performance of English listening.

\section{References}

Arnold, J. (2000). Seeing through listening comprehension exam anxiety. TESOL Quarterly, 34(4), 777-786.

Barron, K., \& Harackiewicz, J. (2001). Achievement goals and optimal motivation: Testing multiple goal models. Journal of Personality and Social Psychology, 80(5), 706-722.

Boyle, J. (2000). Education for teachers of English in China. Journal of Education for Teaching, 26(2), 147-155.

Casanave, C. P. (1988). Comprehension monitoring in ESL reading: A neglected essential. TESOL Quarterly, 22(2), 283-302.

Casanave, C. P. (2010). Taking risks?: A case study of three doctoral students writing qualitative dissertations at an American university in Japan. Journal of Second Language Writing, 19, 1-16.

Elliot, A. J. (1999). Approach and avoidance motivation and achievement goals. Educational Psychologist, 34, 169-189.

Elliot, A. J., \& McGregor, H. A. (2001). A 2 x 2 achievement goal framework. Journal of Personality and Social Psychology, 80, 501-519.

Ericsson, K. A., \& Simon, H. A. (1980). Verbal reports as data. Psychological Review, 87(3), 215-251.

He, T. H. (2008). Reading for different goals: The interplay of EFL college students' multiple goals, reading strategy use and reading comprehension. Journal of Research in Reading, 31(2), 224-242.

Herrmann, B. A. (1992). Teaching and assessing strategic reasoning: Dealing with the dilemmas. The Reading Teacher, 45(6), 428-433.

Kachru, B. B. (1985). Standards, codification, and sociolinguistic realism: The English language in the Outer Circle. In R. Quirck and H. Widdowson (Eds.), English in the world: Teaching and learning the language and literatures (pp. 11-30). Cambridge: Cambridge University Press.

Kachru, B. B. (1997). World Englishes and English-using communities. Annual Review of Applied Linguistics, 17, 66-87.

Kitayama, S., Duffy, S., \& Uchida, U. (2007). Self as cultural mode of being. In S. Kitayama and D. Cohen (Eds.), Handbook of cultural psychology (pp. 136-174). New York: Guilford Press.

Kitayama, S., Park, H., Sevincer, A. T., Karasawa, M., \& Uskul, A. K. (2009). A cultural task analysis of implicit independence: Comparing North America, Western Europe, and East Asia. Journal of Personality and Social Psychology, 97(2), 236-255.

Markus, H. R., \& Kitayama, S. (1991). Culture and the self: Implications for cognition, emotion, and motivation. Psychological Review, 98, 224-253.

Pastor, D. A., Barron, K. E., Miller, E. J., \& Davis, S. L. (2007). A latent profile analysis of college students' achievement goal orientation. Contemporary Educational Psychology, 32, 8-47.

Pintrich, P. (2000). Multiple goals, multiple pathways: The role of goal orientation in learning and achievement. Journal of Educational Psychology, 92(3), 544-555. 
Pintrich, P. (2003). A motivational science perspective on the role of student motivation in learning and teaching contexts. Journal of Educational Psychology, 95(4), 667-686.

Shang, H. F. (2008). Listening strategy use and linguistic patterns in listening comprehension by EFL learners. The International Journal of Listening, 22, 29-45.

Shen, F. Y. (2003). 英语专业四级考试全真试题精解 (Test for English majors: Grade 4). Xi'an, China: World Publishing Corporation.

Shi, X. Y. (Ed.). (2006). 新世纪高等院校英语专业本科生系列教材听力教程 (第三册) 学生用书 (A listening course: Book 3. Student's book). Shanghai, China: Shanghai Foreign Language Education Press. 